\title{
PORT PERFORMANCE PREDICTION THROUGH MARITIME OPERATIONS SIMULATION
}

\author{
Ma Izaskun Benedicto, PROES Consultores, ibenedicto@proes.engineering \\ Rafael M. García Morales, PROES Consultores, rgarcia@proes.engineering \\ Javier Marino, FCC Industrial, JMarinoR@fcc.es \\ Francisco de los Santos, Algeciras Port Authority, fsantos@apba.es
}

\section{INTRODUCTION}

In recent decades, international shipping trade has grown considerably and ports have been extended in order to satisfy the demands of new ships and cargo. Port management has become a difficult task due to the high number of simultaneous operations in ports and the random nature of the agents that are involved in port operations (climate agents, ship arrivals). This makes necessary an aid-decision making tool that reproduces maritime operations and estimates the uncertainty of the port performance.

In this work, the software, based on the methodologies proposed in Benedicto et al (2013) and García Morales et al (2015), is presented. The software has a userfriendly interface, reproduces port operations for a given case and provides a set of indicators that measure the performance of the simulated case, like waiting times or occupancy of berths and harbor services. Port performance is characterized from a statistical point of view. Software validation, with Algeciras Port (Spain) as pilot port, is also presented.

\section{THE SOFTWARE}

The software comprises several modules to (1) define the case study, (2) reproduce port operations, (3) analyze the results and (4) compare different scenarios. The case study is defined by the (i) harbor configuration (channels, docks, anchorages, etc.); (ii) the climate historic data-base -used to simulate the climate conditions that affect ship operations-; (iii) ship traffic, characterized, among other variables, by ship arrivals, dimensions or port services demand; (iv) harbor services offered by the port, namely, pilots and tugs assistance and mooring and ( $v$ ) management and operational criteria, such as priorities or safety procedures.

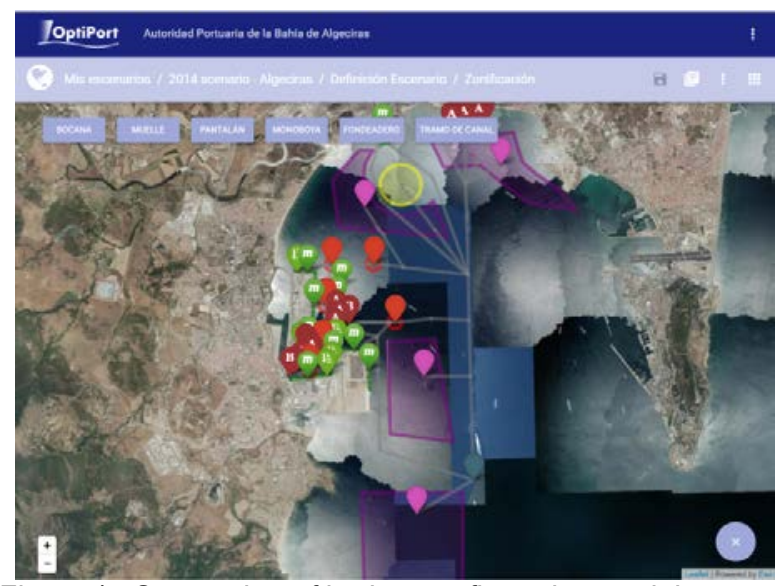

Figure 1 - Screenshot of harbor configuration module

Once the case study is defined, the software reproduces during a certain time interval (one year) the time series that define the climate and exploitation variables (ship arrivals, dimensions, demanded services, etc.). With that information, the software reproduces ship movements at the harbor. To do so, it checks the viability of each movement considering operational criteria (climate thresholds, priorities ...) and availability of resources (harbor services, berths ...). The ship will be able to proceed or will have to wait, and the information will be registered accordingly for every ship during the time interval of simulation.

The previous step is reproduced a large number of times so that a representative sample of the harbor performance indicators is obtained. This sample is then used to infer the distribution functions that characterize in probabilistic terms the behavior of the case.

The software can be applied to different alternatives of a case and used to select the best alternative taking into account multiple criteria and their stochastic character.

\section{VALIDATION CASE}

The software has been validated with a real case study. The Port of Algeciras is located at the south of Spain, in the strait of Gibraltar. The port has been modelled with the software, using the information provided by the Port Authority (docks and berths, ships arrivals and their characteristics, port services, etc.) for the year 2014. This information was also used to obtain some parameters to measure the port performance, such as berth occupancy rate or occupancy rates and use of harbor services. The values obtained from the simulations were compared to the real calculated values. In Figure 2, the annual percentage of time in which $N$ resources are providing simultaneously a specific port service is shown. Real values as well as simulated ones are shown.

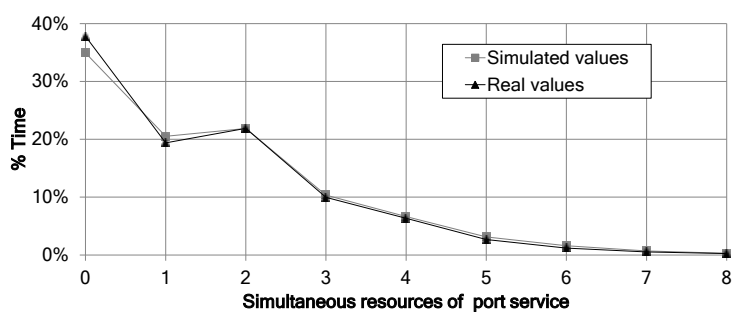

Figure 2 - Time vs Simultaneous use of resources

\section{CONCLUSIONS}

The presented software, which reproduces the port performance accurately, has proven to be a useful decision support tool for port management and planning.

\section{REFERENCES}

Benedicto, Baquerizo, Santos, Sanchidrián, Losada (2013): Software de optimización de la operatividad portuaria mediante técnicas de simulación. XII Jornadas Españolas de Ingenierías de Costas y Puertos.

García Morales, Baquerizo, Losada (2015): Port management and multiple-criteria decision making under uncertainty. Ocean Engineering, Vol.104, pp. 31-39. 